OMEGA, Vol. 61(4) 273-289, 2010

\title{
THE DUAL PROCESS MODEL OF COPING WITH BEREAVEMENT: A DECADE ON*
}

\author{
MARGARET STROEBE \\ HENK SCHUT \\ Utrecht University, The Netherlands
}

\begin{abstract}
The Dual Process Model of Coping with Bereavement (DPM; Stroebe \& Schut, 1999) is described in this article. The rationale is given as to why this model was deemed necessary and how it was designed to overcome limitations of earlier models of adaptive coping with loss. Although building on earlier theoretical formulations, it contrasts with other models along a number of dimensions which are outlined. In addition to describing the basic parameters of the DPM, theoretical and empirical developments that have taken place since the original publication of the model are summarized. Guidelines for future research are given focusing on principles that should be followed to put the model to stringent empirical test.
\end{abstract}

It is gratifying to know that precisely a decade after the publication of our Dual Process Model of Coping with Bereavement (DPM; Stroebe \& Schut, 1999), interest in this model has grown to the extent that a Special Issue in Omega: Journal of Death and Dying is deemed appropriate. Within the past decade various research teams have taken up the challenge both to apply and to test the model, as represented in the following articles in this Special Issue. A scientific model

*Parts of this article have been adapted and updated (with permission) from a more detailed review of the DPM by Stroebe and Schut in Grief Matters: The Australian Journal of Grief and Bereavement, 2008, 11, 1-4.

(c) 2010, Baywood Publishing Co., Inc.

doi: 10.2190/OM.61.4.b

http://baywood.com 
of this kind is no use unless it can be implemented, and being firm empiricists ourselves, we have always considered it essential to put the model to the test. In our view, this should be undertaken first and foremost by research teams independent of our own, and this, fortunately, is what has occurred. The articles in this volume represent an excellent variety of different types of investigation of the model's parameters.

To understand the significance of these contributions, some background information about the DPM is necessary. Thus, in this article, we first describe the rationale for the DPM and summarize its main parameters. We compare and contrast it with other models along a number of dimensions. Throughout, we indicate where further developments and empirical examinations have taken place during the past decade. We end with suggestions for future research directions, focusing on principles that should be followed to put the model to stringent empirical test.

\section{RATIONALE FOR DEVELOPMENT OF THE DPM}

Our purpose in developing the DPM was to provide a model that would better describe coping and predict good versus poor adaptation to this stressful life event, and by doing so, to better understand individual differences in the ways that people come to terms with bereavement. It is a model, then, of coping with loss, not a generic model aimed at explaining the broad range of phenomena and manifestations associated with bereavement. Coping refers to processes, strategies, or styles of managing (reducing, mastering, tolerating) the situation in which bereavement places the individual. Coping is assumed to impact on adaptation to bereavement. If coping is effective, then not only the suffering, but also the mental and physical ill health difficulties that are associated with bereavement (Stroebe, Schut, \& Stroebe, 2007) should be reduced (in time, usually after quite some struggle and turmoil). To understand its impact on outcome, coping must be considered a separate entity from the consequences of bereavement: the former is a process, the latter an outcome variable. Thus (and we return to this later) it becomes essential to differentiate coping (process) from consequences (outcomes) in our empirical investigations. Overall, then, in constructing the DPM, the aim was to postulate regularities in coping processes that are predictive of (non)adaptive outcomes.

At the time when the DPM was developed, there were a number of models available that addressed how people go about coming to terms with bereavement (for a review, see Stroebe, in press). Each of these provided guidelines to understand what needs to be done for successful outcome to occur. Among these, the most influential and appealing coping models in the bereavement area during the latter part of the 20th century were the Phase Model (e.g., Bowlby, 1980, see also Parkes, 1972/1996), which was fundamental to attachment theory, and the Task Model (Worden, 1982, 1991, 2002, 2009), which became prominent 
in the planning of counseling and therapy programs for bereaved people in need of help. Working through grief (known as "grief work," following Freud, 1917/1957) was a fundamental notion underlying the development of both the phases and tasks that are integral to these models (see Figure 1, left hand and middle columns). Grief work is understood to refer to the cognitive process of confronting the reality of a loss through death, of going over events that occurred before and at the time of death, and of focusing on memories and working toward detachment from (or relocating) the deceased (Stroebe, 1992). Following this, it was understood that one has to confront the experience of bereavement in order to come to terms with loss and avoid detrimental health consequences. It was in large part due to consideration of these grief work models - with respect to their major strengths but also their perceived limitations - that led us to develop the DPM. As such, and as will become evident, the DPM built on and extended these earlier conceptualizations.

Despite the useful guidelines that these prior models evidently offered, we had major concerns about the adequacy of their central construct of grief work in explaining adaptive ways of coping with bereavement. First, there are alternative ways of coming to terms with bereavement. As examinations of certain nonWestern cultural patterns of grieving show, the types of confrontation involved in grief work are not universal, nor is non-confrontation systematically linked with mal-adaptation. Second, the process itself as described in the Phase Model (far less so in the Task Model) seems somewhat passive (as though the person is being put through, rather than actively dealing with), neglecting the effortful struggle that is so much part of grieving. Third, there is no acknowledgment of the need for "dosage" of grief. It is arduous and exhausting to grieve, respite at times is recuperative. Fourth, the benefits of denial have not been taken into account (cf. Bonanno, 2001). Fifth, the grief work notion focuses on the loss of the loved person him- or herself, neglecting the possibility that there may be other sources of stress that arise indirectly following a bereavement (e.g., concerns with finances, legal matters, or upbringing of children as a single parent). Furthermore, our own research had failed to show evidence that persons who were doing grief work adjusted better (W. Stroebe, Schut, \& Stroebe, 2005). Finally, different types of "working through" appeared to help different subgroups (Schut, Stroebe, de Keijser, \& van den Bout, 1997), suggesting the need for a more nuanced approach to understanding effective coping. Our conclusion was that the grief work model needed revision to define when and for whom - and in what wayworking through is efficacious. ${ }^{1}$ This reasoning led to the DPM.

\footnotetext{
${ }^{1}$ Bonanno and Kaltman's (1999) integrative perspective on bereavement also replaced what they viewed as a too-narrow focus on the grief work hypothesis (highlighting a lack of empirical evidence). For a critical appraisal of their approach in comparison with the DPM, see Archer (2001).
} 


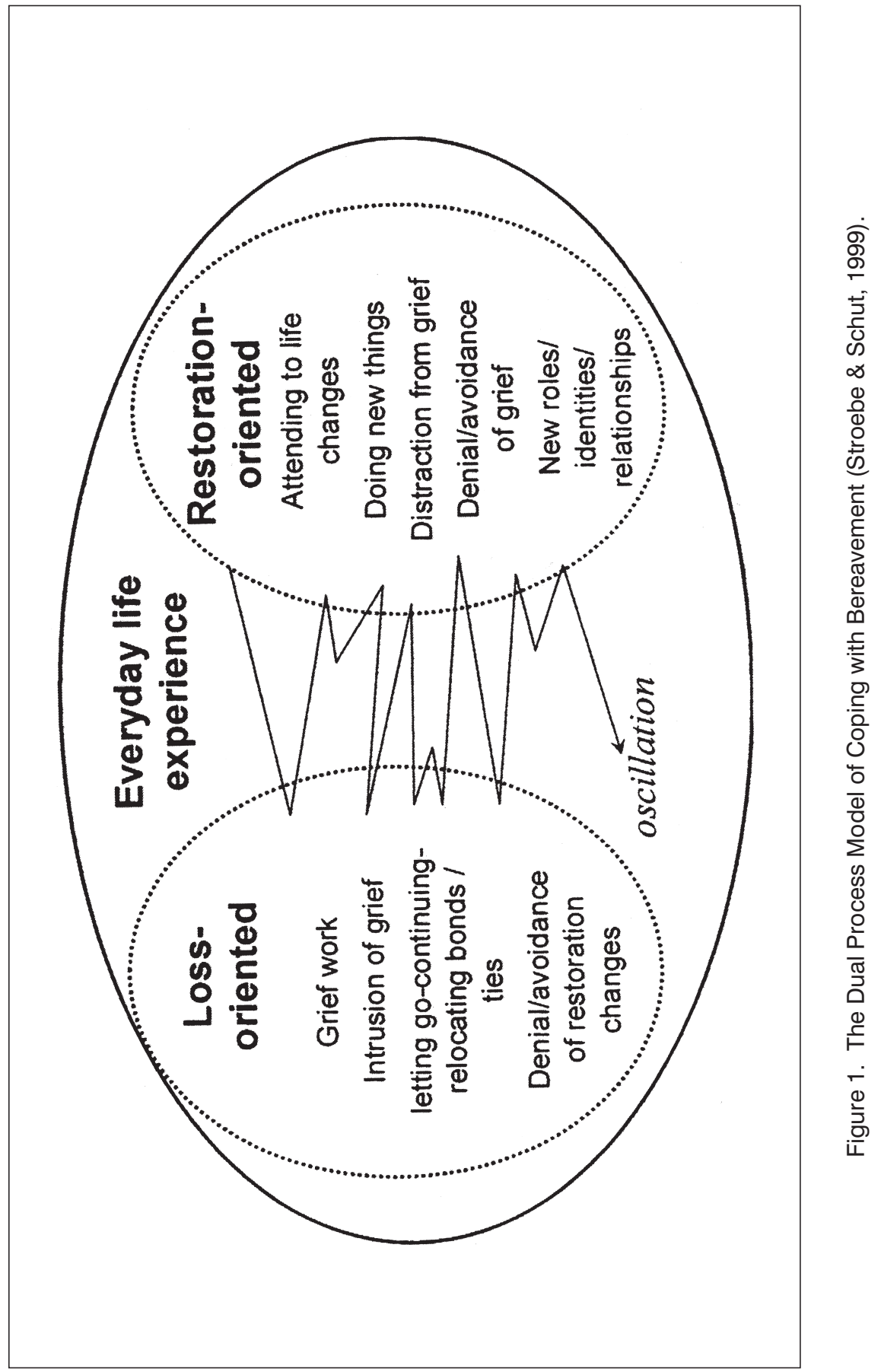




\section{DESCRIPTION OF THE DPM: MAIN PARAMETERS}

The DPM can be understood as a taxonomy to describe ways that people come to terms with the loss of a loved one (for detailed accounts, see Stroebe \& Schut, 1999, 2001). The structure of the DPM parameters owes much to Cognitive Stress Theory (see Folkman, 2001; Lazarus \& Folkman, 1984), particularly insofar as it defines a number of key components related to coping. These are: stressors (the nature of the events leading to stress, i.e., the cause, reason for the coping process to be set in motion); appraisal processes (assessment of threat); coping processes (ways of dealing with threat); and outcome variables (e.g., mental and physical health indices). A fundamental contrast with earlier models is that the DPM defines two categories of stressors associated with bereavement, namely, those that are loss- versus restoration-oriented. Loss-orientation refers to the bereaved person's concentration on, appraising and processing of some aspect of the loss experience itself and as such, incorporates grief work. It involves a painful dwelling on, even searching for the lost person, a phenomenon that lies at the heart of grieving. Restoration-orientation refers to the focus on secondary stressors that are also consequences of bereavement, reflecting a struggle to reorient oneself in a changed world without the deceased person. Rethinking and replanning one's life in the face of bereavement (a part of restoration orientation) can also be regarded an essential component of grieving (cf. Parkes's psychosocial transition theory, e.g., 2006). Caserta and Lund (2007) were able to demonstrate that attention was paid to both types of stressors among a sample of widowed persons, and to indicate that these were related to bereavement outcomes, as did Wijngaards, Stroebe, Stroebe, Schut, van den Heijden, et al. (2008).

It is important to note that loss- and restoration-oriented coping are not equivalent to the Cognitive Stress Theory concepts of emotion- and problem-focused coping (cf. Billings \& Moos, 1981, 1984; Folkman, 2001), although at first sight, one might think that emotion-focused coping seems more loss-oriented, problemfocused coping more restoration-oriented. Emotion-focused coping is directed at managing the emotion that results from stress, problem-focused coping is directed at managing and changing the problem causing the distress (Folkman, 2001; Lazarus \& Folkman, 1984). Indeed, some aspects to do with loss orientation may be better dealt with in an emotion-focused manner (e.g., unchangeable things, such as relating to the fact that the deceased cannot be brought back), but other loss-related experiences can also be dealt with in a problem-focused manner (e.g., to keep the deceased close, one can plant and nurture a tree in his/her memory). Likewise, both emotion- and problem-focused strategies can be employed in coping with restoration stressors. For example, consider the need to repair the financial situation following loss of a spouse's income: Either one can deal with this in an emotion-focused way by worrying and feeling anxious but doing nothing about it, or one can take steps to solve the problem by earning 
money oneself. It becomes evident that many loss- and restoration-stressors can be dealt with either in an emotion- or a problem-focused manner (and in fact, both types are typically used: sometimes the former, sometimes the latter will be more deemed appropriate when dealing with loss- or restoration-stressors).

Both orientations are sources of stress and can be associated with outcomes such as distress and anxiety. Both are also involved in the coping process, for example, they are attended to (confronted versus avoided) in varying degrees (according to individual and cultural variations). The process of attending to or avoiding these two types of stressor is dynamic and fluctuating, and it also changes over time. Therefore, the DPM specifies a dynamic coping process, namely, a regulatory process labeled oscillation, which distinguishes it from the earlier bereavement models (and also from the more generic cognitive stress theory). The principle underlying oscillation is that at times the bereaved will confront aspects of loss, at other times avoid them, and the same applies to the tasks of restoration. Sometimes, too, there will be "time out," when the person is not grieving. Coping with bereavement according to the DPM is thus a complex regulatory process of confrontation and avoidance. An important postulation of the model is that oscillation between the two types of stressors is necessary for adaptive coping. The structural components described above are depicted in Figure 1. Table 1 compares the DPM with the previous models, illustrating restoration stressors that need to be dealt with in addition to those postulated in the Task Model.

At this point in the development of the model, the primary strategy of coping with the loss and restoration stressors was understood to relate to emotion

Table 1. Comparison of Models

\begin{tabular}{lll}
\hline $\begin{array}{l}\text { Phase Model } \\
\text { (Bowlby, 1980) }\end{array}$ & $\begin{array}{l}\text { Task Model } \\
\text { (Worden, 1991) }\end{array}$ & $\begin{array}{l}\text { DPM } \\
\text { (Stroebe \& Schut, 1999) }\end{array}$ \\
\hline Shock & $\begin{array}{l}\text { Accept reality of } \\
\text { loss }\end{array}$ & $\begin{array}{l}\text { Accept reality of loss . . and } \\
\text { accept reality of changed world. }\end{array}$ \\
Yearning/protest & $\begin{array}{l}\text { Experience pain } \\
\text { of grief }\end{array}$ & $\begin{array}{l}\text { Experience pain of grief . . and } \\
\text { take time off from pain of grief. }\end{array}$ \\
Despair & $\begin{array}{l}\text { Adjust to life } \\
\text { without deceased }\end{array}$ & $\begin{array}{l}\text { Adjust to life without deceased ... } \\
\text { and master the changed } \\
\text { (subjective) environment. }\end{array}$ \\
Restitution & $\begin{array}{l}\text { Relocate deceased } \\
\text { emotionally and } \\
\text { move on }\end{array}$ & $\begin{array}{l}\text { Relocate deceased emotionally } \\
\text { and move on ... and develop } \\
\text { new roles, identities, relationships. }\end{array}$ \\
\hline
\end{tabular}


regulation, or more precisely, to confrontation versus avoidance (a major coping dimension in Cognitive Stress Theory). We extended the original DPM model to include further analysis of types of cognitive processing in a subsequent paper (Stroebe \& Schut, 2001), as depicted in Figure 2. Oscillation between positive and negative affect/(re)appraisal is understood to be an integral part of the coping process, and to be a component of both loss- and restoration-oriented coping. Persistent negative effect enhances grief, yet working through grief, which includes rumination, has been identified as important in coming to terms with loss. On the other hand, positive reappraisals sustain the coping effort. Yet if positive states are maintained relentlessly, grieving is neglected. We drew on the work of Folkman (2001) on positive meaning states, and of Nolen-Hoeksema (2001) on negative appraisals to introduce cognitive pathways into the model.

We continue to believe that processes of confrontation-avoidance are central mechanisms in adjustment to bereavement. One line of our current research is directed toward gaining finer-grained understanding of the types of loss- and restoration-oriented cognitions which are associated with normal versus complicated forms of grieving, focusing on rumination as an avoidance process (see Stroebe, Boelen, van den Hout, Stroebe, Salemink, \& van den Bout, 2007). Relatedly, Boelen and van den Bout (in press) have used their CognitiveBehavioural Model of Complicated Grief (Boelen, van den Hout, \& van den Bout, 2006) to examine assumptions about the role of two types of avoidance in complicated grief, ones which they see as comparable with avoidance of lossand restoration-orientations in our own conceptualization. They described and empirically-tested the role of "anxious avoidance" (avoidance of confrontation with the reality of the loss) and "depressive avoidance" (avoiding engagement in activities that could foster adjustment), dimensions that are clearly compatible with the DPM constructs. Anxious and depressive avoidance emerged as distinct factors and accounted for unique parts of explained variance in grief symptomatology. In our view, their results provide indirect support for our proposition that the two types of stressor are distinct and relevant to adjustment: difficulty in dealing with them is associated with poor outcome. Boelen and van den Bout (in press) provided a fine-grained analysis of pathways between process and outcome variables, to which we return later.

\section{THE DPM IN COMPARISON WITH OTHER MODELS}

Already above, it has become evident that - rather unusually in bereavement research - the DPM draws heavily on pre-existing generic as well as bereavement-specific theories for derivation of its parameters. We consider it a strength that the DPM integrates major theoretical perspectives such as attachment and cognitive stress theories. But does the DPM add substantially to previous models, notably, the Phase and Task Models? Worden (2009), in the 4th edition 


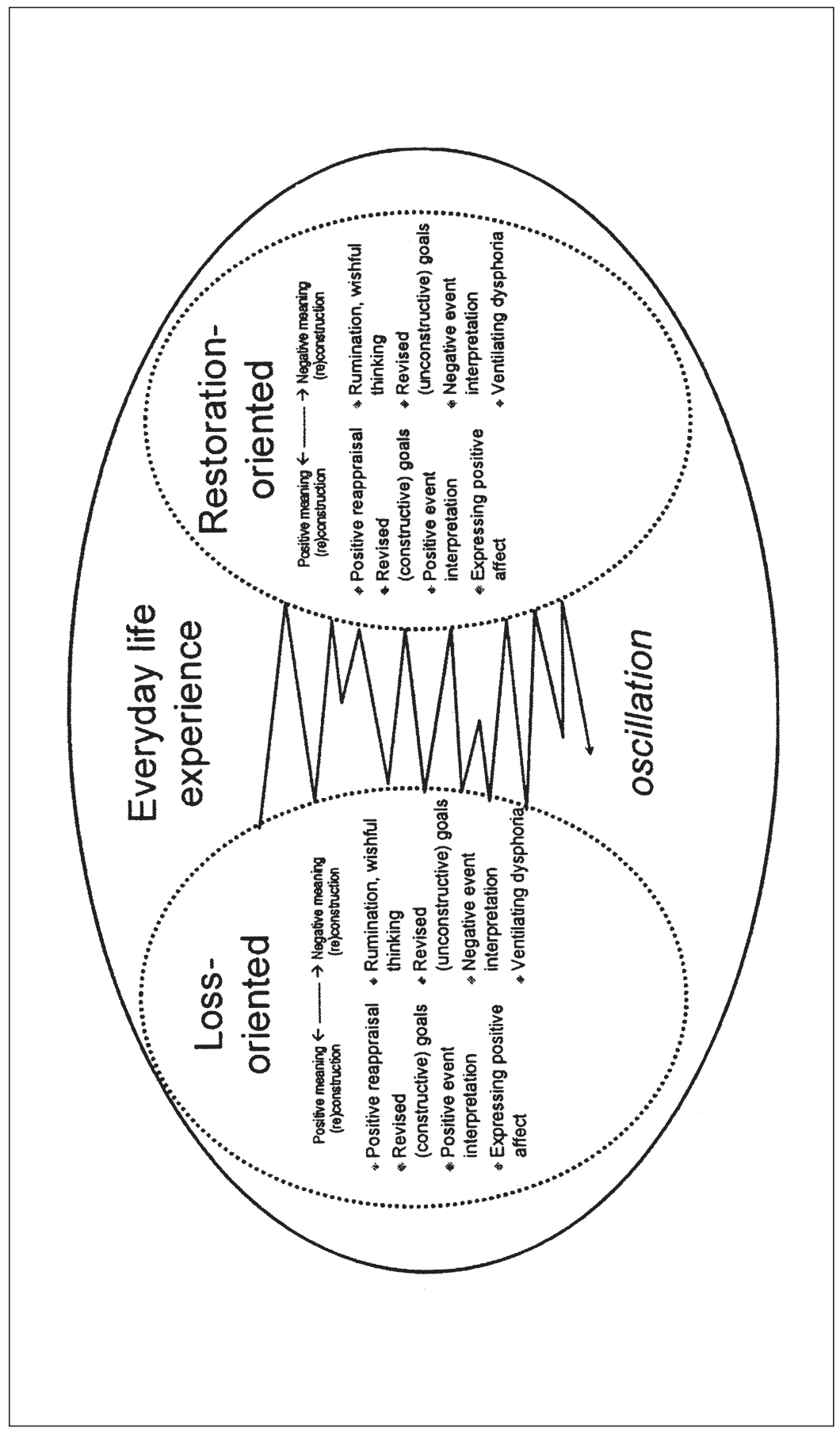

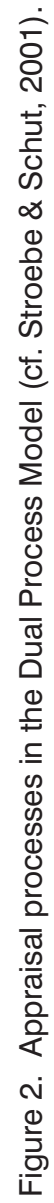


of his monograph, actually argued that there is little difference between his Task Model and the DPM, noting that the tasks are "almost identical" with our stressors. This is more the case for his revised, post-DPM Task Model. Worden's tasks have been reformulated over the years since the DPM was first published, and they are now more explicitly inclusive of restoration stressors, and more in line with our additions in Table 1. Worden's (2009) Task 2 is now: "To process the pain of grief"; Task 3: "To adjust to a world without the deceased"; Task 4: "To find an enduring connection with the deceased in the midst of embarking on a new life" (p. 50). Even though, as evident in these new tasks, there is now more similarity with the DPM, we consider our explicit distinction of the two categories of loss- and restoration-stressors to be unique, to reflect the reality that bereaved people experience, and to be useful for both clinical application and research investigation.

There are a number of other distinguishing features between the models. Worden does not distinguish stressors from coping processes, as we do, or make predictions about (mal)adjustment in relationship specifically to these different component parts. Furthermore, Worden argued that there is similarity in that, according to his model, people go back and forth between his tasks as needed, like our principle of oscillation. Consider oscillation: Although shifting back and forth between the tasks is implicit in his model, merely stating this fails to postulate emotion regulation (confrontation and avoidance) as a fundamental parameter of coping, as we do in our model: The principle of oscillation captures and highlights the necessity for attention to the different categories of stressors. Finally, contrary to what Worden claims, our model posits flexibility (it is fundamental to oscillation), certainly not the "fixed patterns" that he mentions in considering our model, and it caters for individual and subgroup differences (see below).

There are a number of additional respects in which we consider the DPM to add to other formulations, the major ones are briefly described next (for more details, see Stroebe \& Schut, 1999, 2008). First, the DPM provides a framework for understanding forms of complicated grief, such as chronic, or absent, delayed, inhibited grief (cf. Lindemann, 1944; Parkes \& Weiss, 1983) in a way that was not nearly so differentiated or explicit in the previous models, with chronic grievers focusing on loss, absent grievers on restoration-oriented activities, while those who suffer a complicated form of traumatic bereavement might be expected to have trouble alternating smoothly between loss- and restoration-orientation, manifesting extreme symptoms of intrusion and avoidance (for details, see Stroebe \& Schut, 2008). It is important to note that in both loss-oriented (e.g., chronic) and restoration-oriented (e.g., absent) types of complicated grief, reactions are extreme, with extensive focus on the one orientation and avoidance of the other. Such patterns are associated with an absence of the type of confrontation-avoidance (oscillation) that we have described as characteristic of "normal" coping with bereavement. In general, there are substantial individual 
differences in the extent to which (normally) bereaved persons focus on lossor restoration-orientation: only in extreme cases of confrontation of the one, and avoidance of the other are complications in grieving and poor adaptation likely to occur.

In recent publications, the relationship between complicated grief and patterns of attachment has been explored within the context of the DPM (e.g., Mikulincer \& Shaver, 2008; Parkes, 2006; M. Stroebe, Schut, \& W. Stroebe, 2005). In fact, one of the most important developments of the DPM has emerged from exploration of its links with attachment theory constructs (e.g., Mikulincer \& Shaver, 2008; Parkes, 2006; Stroebe, Stroebe, \& Schut, 2005; Stroebe, Schut, $\&$ Stroebe, 2005a), and some empirical evidence has accumulated in support of these connections in the meantime (see Stroebe \& Schut, 2008). We have also explored how attachment style differences influence patterns of disclosure in coping with bereavement (see Stroebe, Schut, \& Stroebe, 2005b).

Turning next to (sub)group differences: As described in Stroebe and Schut (1999), the DPM also accommodated male and female differences in ways of grieving better than the previous models described above and, more recently, we have explored gender differences in coping with bereavement in relationship to health outcomes, using the DPM framework (see Stroebe, Stroebe, \& Schut, 2001). Women appear to be more loss-oriented following bereavement, feeling and expressing their distress at their loss; men more restoration-oriented, actively engaging with the problems and practical issues associated with loss (Wijngaards et al., 2008; cf. Parkes, 2006). Again it is important to note that focusing on lossorientation among women and restoration-orientation among men may generally work well, unless one or other orientation is adhered to in the extreme (indicated by an absence of oscillation to the other orientation).

Contrary to subsequent criticism that the DPM is an intra-personal model (like the preceding models), in our 1999 paper we already described interpersonal coping processes that the model has the potential to incorporate, acknowledging that one person's way of grieving impacts on that of another. The gender differences described above provide an illustration: if, say, a bereaved father is more restoration-oriented, a mother more loss-oriented, attributions may be made in terms of differences in extremity of grief, for example, a mother might assume "he is grieving less than I am" rather than what may actually be the case, that "he is grieving differently." Making the former attribution could negatively impact the couple's adjustment to bereavement. More recent evidence regarding the influence of such interpersonal coping processes from a DPM perspective has been found: Wijngaards et al. (2008) used the DPM framework to examine the relationship between a bereaved parent's own and their partner's way of coping in relationship to their adjustment to the death of their child. Interpersonal factors were indeed found to play a part in coping and adjustment. For example, one of the main findings was that, for fathers, having a wife who was high in restoration-oriented coping was related to positive adjustment. 
We mentioned earlier that cultural differences in ways of working through grief were a major reason for the need to revise earlier conceptions. Cultures vary according to the norms/belief systems which govern manifestations and expressions of grief. These can be understood according to loss- versus restorationoriented coping. A clear example has been provided by the anthropologist Wikan (e.g., 1988). The Muslim community on the island of Bali would be described as restoration-oriented, showing little or no overt sign of grief and outwardly continuing daily life as though nothing untoward had happened. By contrast, the Muslim community in Egypt expresses their grief openly, gathering together to reminisce and share anguish over their loss. Other vivid examples of such cultural differences that are compatible with our DPM formulation can be found in Rosenblatt (2008).

Although we also mentioned changes in patterns of coping over time, in our 1999 article we did not elaborate much on this aspect. It is important to note that, like the Phase and Task Models, changes are expected across the duration of bereavement according to the DPM. There will gradually (and unevenly) be less attention to loss-oriented and more to restoration-oriented tasks. For example, early in bereavement there is generally comparatively little attention to forming a new identity and far more to going over the events to do with the death, while over time a gradual reversal in attention to these different aspects is likely to take place. Furthermore, as time goes on, the total amount of time spent on coping with loss and restoration tasks will diminish. Some evidence for these patterns is now available (e.g., Caserta \& Lund, 2007; Richardson \& Balaswamy, 2001; Stroebe \& Schut, 2008). Of course, both the Phase and Task Models incorporate changes over time too, but without specifying these so explicitly in relationship to different types of stressors.

We originally formulated the DPM to address coping after partner loss, since this had been the focus of our empirical research before that time. By contrast, the other models were not limited to any particular type of loss (of a child, parent, spouse, etc.), and we have come to realize that this is probably also the case for application of the DPM. Indeed, more recently we have explored application of the model to partners coping with the death of their child (e.g., Wijngaards et al., 2008 ) and to bereavement specifically among the elderly (Hansson \&. Stroebe, 2007). Other teams of researchers have addressed additional types of bereavement, for example, Stokes, Pennington, Monroe, Papadatou, and Relf (1999) have applied the DPM to children and other family members. We have also suggested its application to the phenomenon of homesickness, which can be regarded as a "mini-grief" experience (Stroebe, van Vliet, Hewstone, \& Willis, 2002). We have sometimes been asked about the applicability of the DPM to other stressful life events, such as divorce or dealing with the chronic illness of a loved one. There are certain parallels across such different types of events in loss and restoration domains, but it remains for researchers and clinicians to explore the usefulness of the DPM to them empirically. 


\section{GUIDELINES FOR TESTING THE DPM}

Although the DPM looks quite straightforward as presented in Figure 1, it is difficult to test its parameters and/or empirically examine the relationship of the postulated coping processes to bereavement outcomes. The guidelines are summarized in Table 2.

\section{Differentiating Stressors, Coping, and Outcome}

Given that we have postulated two different categories of stressors, loss- and restoration-oriented, a useful direction for research is simply first to show that bereaved people actually have to deal with aspects that fall within these two categories: here, the focus is not on coping strategies or on the outcomes of dealing with them, but on the (range of) experiences that have to be dealt with, per se, the stressors. Thus, in doing such research, it is important to keep clear that the loss or restoration stressors are not equivalent to "coping with" or "being restored." An example hopefully makes this distinction clearer. Consider one restoration stressor, namely, the problem of changed identity from wife to widow: the stressor

Table 2. Recommended Guidelines for Testing the DPM: Summary

- Separate stressors from process from outcome variables (e.g., make sure no symptoms are included among coping items).

- Best test of relationship between DPM coping and outcome involves maladjusted versus adjusted bereaved persons.

- Observe scientific design principles: (e.g., control groups-e.g., non-intervention control groups in intervention studies; longitudinal investigation: before, after, and follow-up).

- Extend beyond questionnaire measures (mobile phones, mobile internet, PDA's for monitoring; diaries; intervention principles, etc.).

- Specify (in definitions and operationalizations) the precise parameter under investigation (the two types of stressors; coping processes; oscillation process; coping in relationship to outcome).

- Integrate other theoretical perspectives to refine DPM predictions.

- Keep in mind that:

- Normal reactions can vary greatly between individuals and groups with respect to preferred focus on loss- versus restoration tasks: for some loss-orientation will dominate, for others, restoration-orientation.

- Only in cases of extreme, unrelenting, exclusive adherence to (focus on) one or the other type of stressor, or in cases of disturbance of the oscillation process itself, will maladaptation occur.

- Loss- and restoration-orientation are not equivalent to emotion- and problem-focused coping. 
should be formulated in words such as "I have trouble finding a place in life without my spouse." Coping with this stressor would be tapped with items such as "I avoid going on dates with potential new partners," while "I have a new identity or role in life" indicates outcome.

\section{Assessing Oscillation}

It is not easy to investigate the process of oscillation since it is a dynamic process of confrontation and avoidance that can change not only from moment to moment, but also in relationship to the duration of bereavement. Methods other than questionnaire investigations are thus advisable. Questionnaire items asking about shifting attention from loss- to restoration-oriented stressors have sometimes been used, but rather these fail to capture the dynamics of oscillation. Some suggestions would be to use:

- Cell phones, mobile internet, personal digital assistants (PDA's); diaries, and time sampling (these may indeed usefully include — but not necessarily be limited to-questionnaires).

- Laboratory techniques to induce shifting (e.g., by presenting stimuli to do with the loss, and then to do with restoration).

\section{Examining DPM Parameters in Relationship to Outcome}

It is important to note that there are individual differences in the amount of attention paid to $\mathrm{LO}$ and $\mathrm{RO}$ stressors within the normal range of reactions to bereavement: some will have a tendency/preference to focus more on their loss, others more on restoration tasks; some will spend much time, others little time on either or both of these dimensions. Within a moderate range, that is, one that does not exclude attention to either or both types of stressor, the prediction will be that persons adapt to loss in time. Only in extreme cases, such as focusing unremittingly and exclusively on loss, will there be poor outcome. It follows from this that the best test of the DPM will be to compare samples of persons experiencing poor outcomes such as complicated grief with those who are undergoing a normal grief process. The DPM postulates a number of patterns that will be predictive of poor outcome, and which could be used to formulate hypotheses:

1. extreme attention to (i.e., coping with) loss orientation, avoidance of restoration

2. extreme attention to (i.e., coping with) restoration orientation, avoidance of loss

3. high scores on 1 and 2 and no "time off"?

4. disturbance of oscillation (disturbed intrusion-avoidance)

5. high scores on the number of stressors (could be both LO and RO) 
The DPM coping-adaptation research paradigm described here can be conducted on an interpersonal level. For example, the Wijngaards et al. (2008) investigation cited earlier investigated differences in adaptation among couples as a function of the amount of loss- versus restoration-oriented coping of each member of the couple. Clearly, additional hypotheses need to be developed to make couple-level predictions as in this latter project.

It is also important to remember that outcomes can include a variety of consequences besides normal and complicated grief. It is important to look beyond manifestations of grief and even other symptoms (depression, anxiety, physical health symptoms, etc.), to think in terms of broader aspects relating to personal functioning, such as outcome acceptance (i.e. ...), sense of control, self-efficacy, relationship/marital satisfaction, attachment, and emotional equilibrium.

\section{Research Design Features for Testing the DPM}

We have already mentioned a number of features for the design of empirical tests of the DPM. In addition, it is important to stress that longitudinal, preferably prospective designs should be used in order to establish what is cause and what is effect. When it comes to testing the effects of intervention using the DPM, it goes without saying that randomized controlled trials are necessary. This brings us to our next point.

\section{Intervention Principles: A Test of the DPM}

Following DPM principles, if the bereaved person is suffering from complications in their grieving process, intervening to change his or her pattern of confronting versus avoiding loss- and restoration-stressors should lead to better adjustment. This is precisely what Shear, Frank, Houck, and Reynolds (2005) did. They used the DPM as a guideline for designing one intervention program (labeled Complicated Grief Treatment, CGT) and evaluated the efficacy of this program against an established one (Interpersonal Psychotherapy, IPT). The therapist described the DPM to clients with complicated grief and emphasized the need to focus on restoration as well as loss tasks, which were both addressed in the therapy sessions. The DPM-type CGT intervention was more effective (even) than IPT. This suggests that the processes identified in the DPM may indeed be central in coming to terms with bereavement. Again, the authors emphasize the need for follow-up investigation, and indeed, it is too early to conclude that the DPM base was the or even $a$ success factor. Furthermore, in the absence of a non-bereaved control, one cannot be sure that either the CGT or IPT interventions were really effective for treating CG. Nevertheless, this study is an excellent start and good example of how DPM parameters can be included and tested in intervention.

Testing DPM (see Table 2) using intervention should focus on high risk groups or those with complicated grief (see Schut et al., 1997; Schut \& Stroebe, 2005). 


\section{CONCLUDING REMARKS}

There is enormous scope for further research on the DPM, and, in our view, the best way forward is to follow the sorts of guidelines that we have outlined above. Both theoretical and empirical contributions are needed, the former to refine and extend the DPM framework and further identify specific underlying cognitive processes, the latter to test the model's parameters and their power in predicting good versus poor adjustment to bereavement. The input of different research teams - such as those illustrated in the following articles in this Special Issuewill be invaluable in this endeavor.

\section{REFERENCES}

Archer, J. (2001). Broad and narrow perspectives in grief theory: Comment on Bonanno and Kaltman (1999). Psychological Bulletin, 127, 554-560.

Billings, A., \& Moos, R. (1981). The role of coping resources and social resources in attenuating the stress of life events. Journal of Behavioral Medicine, 4, 139-157.

Billings, A., \& Moos, R. (1984). Coping, stress, and social resources among adults with unipolar depression. Journal of Personality and Social Psychology, 46, 877-891.

Boelen, P. A., \& van den Bout, J. (in press). Anxious and depressive avoidance and symptoms of prolonged grief, depression, and Post Traumatic Stress-Disorder. Psychologica Belgica.

Boelen, P. A., van den Hout, M. A. \& van den Bout, J. (2006). A cognitive-behavioral conceptualization of complicated grief. Clinical Psychology: Science and Practice, 13, 109-128.

Bonanno, G. (2001). Grief and emotion: A social-functional perspective. In M. S. Stroebe, R. O. Hansson, W. Stroebe, \& H. Schut (Eds.), Handbook of bereavement research: Consequences, coping and care (pp. 493-515). Washington, DC: American Psychological Association.

Bonanno, G., \& Kaltman, S. (1999). Toward an integrative perspective on bereavement. Psychological Bulletin, 125, 760-776.

Bowlby, J. (1980). Attachment and loss; Vol. 3, Loss: Sadness and depression. London: Hogarth.

Caserta, M., \& Lund, D. (2007). Toward the development of an inventory of daily widowed life (IDWL): Guided by the Dual Process Model of coping with bereavement. Death Studies, 31, 505-535.

Folkman, S. (2001). Revised coping theory and the process of bereavement. In M. S. Stroebe, R. O. Hansson, W. Stroebe, \& H. Schut (Eds.), Handbook of bereavement research: Consequences, coping and care (pp. 563-584). Washington, DC: American Psychological Association.

Freud, S. (1917/1957). Mourning and melancholia. In J. Strachey (Ed. \& Trans.), The standard edition of the complete works of Sigmund Freud (Vol. 14, pp. 152-170). London: Hogarth Press.

Hansson, R. O., \& Stroebe, M. S. (2007). Bereavement in later life: Coping, adaptation, and developmental influences. Washington, DC: American Psychological Association. Lazarus, R., \& Folkman, S. (1984). Stress, appraisal, and coping. New York: Springer. 
Lindemann, E. (1944). Symptomatology and management of acute grief. American Journal of Psychiatry, 101, 141-148.

Mikulincer, M., \& Shaver, P. (2008). An attachment perspective on bereavement. In M. S. Stroebe, R. O. Hansson, H. Schut, \& W. Stroebe (Eds.), Handbook of bereavement research and practice: Advances in theory and intervention (pp. 87-112). Washington, DC: American Psychological Association.

Nolen-Hoeksema, S. (2001). Ruminative coping and adjustment to bereavement. In M. Stroebe, R. O. Hansson, W. Stroebe, \& H. Schut (Eds.), Handbook of bereavement research: Consequences, coping and care (pp. 545-562). Washington, DC: American Psychological Association.

Parkes, C. M. (1972/1996). Bereavement: Studies of grief in adult life. London: Routledge.

Parkes, C. M. (2006). Love and loss: The roots of grief and its complications. London: Routledge.

Parkes, C. M., \& Weiss, R. (1983). Recovery from bereavement. New York: Basic Books.

Richardson, V., \& Balaswamy, S. (2001). Coping with bereavement among elderly widowers. Omega, 43, 129-144.

Rosenblatt, P. (2008). Grief across cultures: A review and research agenda. In M. S. Stroebe, R. O. Hansson, H. Schut, \& W. Stroebe (Eds.), Handbook of bereavement research and practice: Advances in theory and intervention (pp. 207-222). Washington, DC: American Psychological Association.

Schut, H. A. W., Stroebe, M. S., de Keijser, J., \& van den Bout, J. (1997). Intervention for the bereaved: Gender differences in the efficacy of grief counselling. British Journal of Clinical Psychology, 36, 63-72.

Shear, K., Frank, E., Houck, P., \& Reynolds, C. (2005). Treatment of complicated grief: A randomized controlled trial. Journal of the American Medical Association, 293, 2601-2608.

Stokes, J., Pennington, J., Monroe, B., Papadatou, D., \& Relf, M. (1999). Developing services for bereaved children: A discussion of the theoretical and practical issues involved. Mortality, 4, 291-307.

Stroebe, M. (in press). Coping with bereavement. In S. Folkman (Ed.), Handbook of stress, coping and health. Oxford: Oxford University Press.

Stroebe, M. S. (1992). Coping with bereavement: A review of the grief work hypothesis. Omega: Journal of Death and Dying, 26, 19-42.

Stroebe, M. S., Boelen, P., van der Hout, M., Stroebe, W., Salemink, E., \& van den Bout, J. (2007). Ruminative coping as avoidance: A reinterpretation of its function in adjustment to bereavement. European Archives of Psychiatry and Clinical Neuroscience, 257, 462-472.

Stroebe, M. S., \& Schut, H. (1999). The Dual Process Model of coping with bereavement: Rationale and description. Death Studies, 23, 197-224.

Stroebe, M. S., \& Schut, H. (2001). Meaning making in the Dual Process Model. In R. Neimeyer (Ed.), Meaning reconstruction and the experience of loss (pp. 55-73). Washington, DC: American Psychological Association.

Stroebe, M., \& Schut, H. (2008). The Dual Process Model of Coping with Bereavement: Overview and update. Grief Matters: The Australian Journal of Grief and Bereavement, 11, 1-4.

Stroebe, M., Schut, H., \& Stroebe, W. (2005a). Attachment in coping with bereavement: A theoretical integration. Review of General Psychology, 9, 48-66. 
Stroebe, W., Schut, H., \& Stroebe, M. S. (2005b). Grief work, disclosure and counseling: Do they help the bereaved? Clinical Psychology Review, 25, 395-414.

Stroebe, M., Schut, H., \& Stroebe, W. (2007). Health consequences of bereavement: A review. The Lancet, 370, 1960-1973.

Stroebe, M. S., Stroebe, W., \& Schut, H. (2001). Gender differences in adjustment to bereavement: An empirical and theoretical review. Review of General Psychology, $5,62-83$.

Stroebe, M., Stroebe, W., \& Schut, H. (2005). Who benefits from disclosure? Exploration of attachment style differences in the effects of expressing emotions. Clinical Psychology Review, 26, 66-85.

Stroebe, M., van Vliet, T., Hewstone, M., \& Willis, H. (2002). Homesickness among students of two cultures: Antecedents and consequences. British Journal of Psychology, 93, 147-168.

Wijngaards, L., Stroebe, M. S., Stroebe, W., Schut, H., van den Bout, J., van der Heijden, P., et al. (2008). Parents grieving the loss of their child: Interdependence in coping. British Journal of Clinical Psychology, 47, 31-42.

Wikan, U. (1988). Bereavement and loss in two Muslim communities: Egypt and Bali compared. Social Science and Medicine, 27, 451-460.

Worden, J. (1982/1991/2002/2009). Grief counselling and grief therapy: A handbook for the mental health practitioner (4th ed.). New York: Springer.

Direct reprint requests to:

Margaret Stroebe

Department of Clinical \& Health Psychology

Utrecht University

Box 80140

3508 TC Utrecht, The Netherlands

e-mail: M.S.Stroebe@UU.NL 